\title{
Physical and psychological condition of senior people in a residential care facility. The effects of an aerobic training
}

\author{
Emanuela Rabaglietti ${ }^{1 *}$, Liubicich Monica Emma ${ }^{2}$, Ciairano Silvia $^{1}$ \\ ${ }^{1}$ Department of Psychology, Laboratory of Developmental Psychology, University of TorinoVia Verdi 10, Turin, Italy; \\ *Corresponding Author: emanuela.rabaglietti@unito.it \\ ${ }^{2}$ SUISM-Scuola Universitaria Interfacoltà di Scienze Motorie, Centro Ricerche in Scienze Motorie e Sportive, University of Turin, \\ Turin, Italy
}

Received 31 December 2009; revised 18 January 2010; accepted 20 January 2009.

\section{ABSTRACT}

The present study is aimed at investigating the changes between pre-test and post-test, after having introduced an aerobic programme of physical activity (one session, each of 45 ' per week for 15 weeks, over a span of roughly four months, delivered by specially trained instructor), in the psychological situation (perception of general health, feelings of geriatric depression) and physical condition (activities of daily living, physical performance in terms of balance and gait, weight, and body mass index-BMI) of a group of senior citizens slightly compromised at Mini Mental State Examination (MMSE: median 23) and living in a residential care facility in northern Italy. The 36-Item Short Form Health Survey Questionnaire (SF-36), the Geriatric Depression Scale (GDS), the Italian short version of Barthel's Index of Activities of Daily Living (BADL), the Tinetti Assessment Tool were administered to 18 old men and women (median age 85.50 years). The findings (we used nonparametric statistical techniques) showed that: 1) general health perception, feelings of depression, and activities of daily were stable; 2 ) general physical performance, and particularly the balance, increased between pre-test and post-test, while weight, BMI and waist circumference decreased. These results underline the importance, especially in the case of women, of participating at an aerobic training delivered by experienced instructors for the physical condition of senior citizens, also when they are slightly cognitively compromised.

Keywords: Senior People; Training;
Physical and Psychological Condition

\section{INTRODUCTION}

The participation at training of physical activity in very old people living in residential care facilities may have some effects in terms of the potential positive consequences for the general physical and psychological conditions. On its turn some improvement in the general physical and psychological conditions may enhance the global quality of life and may contribute to the maintenance of cognitive and physical skills and autonomy.

At increasing age we usually observe a progressive decreasing of physical skills [1], which is related to physiological changes [2]. However, at the same age we found great individual differences in the amount of daily living autonomy [3]. Furthermore, at very old ages, the biological potential of the individuals is even further weakened, leading to different forms of frailties $[4,5]$, which contribute to make older people much vulnerable and less apt at mastering the tasks of daily living.

Among the senior people, frailty is a heterogeneous syndrome that includes aspects related to physical functioning, such as walking, balance and strength, metabolic aspects as the body max index, and psychological and cognitive aspects [6,7]. Some recent studies underlined that in elderly people there is a relationship between decreasing of physical abilities and both cognitive decline [8] and modification of the body mass index [9]. More specifically, a increase of the body mass index was found positively related to the development of physical disabilities, especially among women, while the maintenance of a correct body weight was related with high levels of physical functioning, and consequently with a great autonomy in mastering the tasks of daily living [10]. The study by Bohannon and colleagues [11] underlined, 
in a sample of older women aged 74.9 years and living in residential care facilities, a strong relationship between increase in the body mass index and decrease of the physical ability linked to walking. The decrease of such abilities, which is expressed by deficit in strength, resistance and balance, is determinant for the loss of autonomy, leading the older people to dependence in facing the basic activities of daily living [12,13].

Generally speaking, the condition of frailty, particularly in senior citizens who are institutionalized for long period, is often associated to episodes of fall that represent a risk factor not only for the physical disability but also for the potential negative psychological consequences [14,15]. In fact, the loss of self confidence and the fear of falling may accelerate the functional decline and may induce depression [16] and/or isolation, particularly among women and the most old people [17-20]. Besides, the elderly people who repeatedly fall are not only at risk of death, they tend to develop more rapidly than their mates deficits in the skills of successfully mastering basic daily living activities [21].

The benefits of a regular physical activity for the psychological and physical condition of senior citizens have been already widely acknowledged. Among the others, the meta-analysis by McCauley [22] showed that about $69 \%$ of researches published in this field found a positive association between physical activity and the psychological wellbeing of the elderly people. This positive association was confirmed by the meta-analysis by Kramer et al. [1] that paid attention particularly at the positive effects of aerobic training on the cognitive functioning of the senior people. Also the more recent study by Wang and colleagues [9] showed that a increase in physical activity is associated with a decrease in the risk of onset of dementia. Furthermore, some studies on population [3], showed that the association between physical activity and health is especially strong in women and most old groups of people. In general, physical activity contributes to the wellbeing of the person fulfilling a preventive action against the onset of different pathologies, and among these pathologies especially physical disability [23].

According to the indications of the American College of Sports Medicine [24], the programs of physical activity addressed at the elderly people in the residential care facilities are aimed at preserving the abilities of daily living, which are necessary for conserving a certain independence as long as possible, at delaying the onset of chronic pathologies and at promoting the wellbeing of the older people, by offering opportunities of social interactions. Different typologies of exercises were showed able to improving the physical abilities and the quality of life of the senior citizens [25]. Among these exercises particularly effective seem those that require a multilateral approach at physical activity, by proposing specific exercises for joint mobility, balance, strength and resistance, and respecting the individual level of ability.

Despite the relevance of investigating these issues in different samples, the great majority of the studies concentrated on senior citizens aged from 65 and 75 years $[14,22]$. Given the increasing life expectancy in all the western society [26] we think that it is relevant to start to investigate much older samples.

The present longitudinal study represent the continuation of some previous researches [27-29] that demonstrated the positive effect of an aerobic programme of physical activity in an Italian sample of senior citizens in residential care facilities on positive self-perception and the perception that health limits physical activities.

In the present study we further extended our interest focusing on a very old group of people and investigating also measures of physical wellbeing and performance. Specifically, we looked at a group of elderly people, who lived in a residential care facility and who were shown slightly impaired at the Mini Mental State Examination (MMSE), to describe the changes between pre-test and post-test in relation to the participation at an aerobic programme of physical activity, on psychological aspects (such as general health perception and feelings of depression), abilities of daily living, and physical aspects (in terms of balance and gait, weight, body mass indexBMI-and waist circumference).

In relation to the phase of development of very old ages, we have to acknowledge that it is usually characterized by a general slowness of the processes of change, particularly with respect to the self evaluation of physical and psychological condition that may need some time for being appreciated [30]. Besides, also a slight cognitive impairment, as that showed by our participants, may even further slow the appreciation of eventual changes in self-perception because of crystallization of the previous self-evaluation. Thus, we expected that at very old ages the participation at training of aerobic physical activity contributes to modify more the aspects connected to the physical condition, than the psychological dimension such as general health perception, depressive feelings and basic activities of daily living. Besides, we have to consider that very old people living in residential care facilities may have a rather unfavorable balance in terms of resources and/or ties they can count on: they are all institutionalized from long time and therefore they may have lost much of the resources on which usually people count on, as the small daily habits of living independently at home and the daily relationships with the external context. 


\section{METHODS}

\subsection{Study Design}

The intervention was introduced in a residential care facility in northern Italy. It is a private structure but linked to the public health service with a funding agreement. This facility houses both self-sufficient (that is, they can still walk, eat and go in the bathroom by themselves) and dependent (requiring assistance with essential activities of daily living) senior citizens; it also provides the self-sufficient guests a daily physiotherapy session.

\subsection{Description of the Intervention}

The intervention consisted of one session (lasting 45, each) per week for 15 weeks, over a span of roughly four months. The intervention was addressed to a group of self-sufficient elderly people living in a residential care facility. The sessions were conducted by one instructor, she had university degree in physical education and sport-related fields and was specialised in physical fitness training for older people [28].

The aerobic programme aimed to achieve five main goals:

1) to improve respiratory function through deep breathing techniques;

2) to promote the awareness of incorrect or compensative posture and to learn to modify these problems on their own;

3) to execute movements addressed to the various joints, trying to reach the maximum possible exertion, without exceeding personal limitations;

4) to reach a correct perception of one's body in various conditions of static and dynamic equilibrium;

5) to strength interpersonal relationships and rediscover the joys of playing and using abilities that may have been perceived as lost, by exercising in pairs or small groups.

The intervention was tailored to engage gradually and to interest the elderly people in a variety of different kinds of activities, by using both conventional and unconventional instruments (such as stools, sticks, clubs, hoops, balloons, foam balls, towels, paper cups, pins, bowls, paper tissues, scarves, and trays) and by stressing playful qualities. Besides, the instructor was daily informed by the other personnel about the condition of each older person, also in terms of minor physical problems, and they avoided asking for potentially dangerous movements. Furthermore, special care was taken to provide older people with plenty of time to execute each movement, avoiding activities that could have been perceived as too intense, embarrassing, or difficult.

\subsection{The Participants}

The selection of the senior citizens was conducted by the director of the residential care facility, who is a trained physician, from among all the elderly people living in the facility. The two criteria for inclusion were: 1) selfsufficiency (defined as above), and 2) absence of serious chronic and/or acute diseases, which was verified directly by the researchers. The Mini Mental Test Examination (MMSE) was used to evaluate cognitive capacity [7]: the participants were assessed slightly cognitively impaired since the median score was 23 and the range scored between 18 and 24 .

The participants were informed that participation in the study was voluntary and confidential. All the selected senior people agreed to participate and gave informed consent, in accordance with Italian law and the Association of Italian Psychologists' ethical code [31].

The group of participants comprised 18 senior people, of whom $6(33 \%)$ were men and $12(67 \%)$ women. The median age was 85.50 years $($ Mean $=85.86, \mathrm{SD}=5.64$; range 74-96). All the participants lived in the residential care facility permanently. All except one, who was born in the centre of Italy, were from the same region where the facility is located. With regard to marriage status the majority $(\mathrm{N}=11,60 \%)$ were widows, the $28 \%(\mathrm{~N}=5)$ were married and the others had never been married $(\mathrm{N}=$ $1)$, or were divorced $(\mathrm{N}=1)$. In terms of education, two levels were considered: 'low', corresponding to compulsory education (primary and secondary school) and 'high', corresponding to additional non-compulsory education (including high school and university). The average level of education for both men and women in the sample was similar at the national statistics of population for age-matched [19,32]. Among participants, $67 \%$ percent $(\mathrm{N}=12)$ had received compulsory education compared to about 70 percent in the national population. Former occupations were dichotomised in manual $(\mathrm{N}=12,67 \%)$ and non-manual labour $(\mathrm{N}=6,33 \%)$. This ratio closely reflects the national population. The majority $(\mathrm{N}=12,67 \%)$ had never participated in organised exercise or sport activities. Of those who had, the preferred sports were bowls, gymnastic, soccer, and walking.

The administration of the whole set of instruments at the pre-test and post-test was very long (about 3-4 hours for participant including both psychological and physical measures). Thus, we did not succeed in collecting the complete information in 6 participants $(1$ man and 5 women) with respect to the physical measures and in 1 women with respect to the questionnaires because these elderly people cannot participate at all the administration sessions during the weeks planned for pre-test and/or post-test for different reasons, mainly because of suffer- 
ing slight indispositions and/or having became acute again of small affliction. However, we did not find any difference between this subgroup of participants with not complete information and their mates nor with respect to the socio-demographic information, neither with respect to the study variables that we were able to collect.

\subsection{Procedure}

From the Italian version of the 36-Item Short Form Health Survey Questionnaire (SF-36; [33,34]), in the present study we used only the question that investigates the general perception of health (Range of possible answers: 1 bad-5 excellent).

Besides the senior citizens were administered the Italian short version of the Geriatric Depression Scale (GDS; $[15,35])$. This questionnaire consists of 15 items referring to seven common characteristics of depression in older life: somatic concern, lowered affect, cognitive impairment, feelings of discrimination, impaired motivation, lack of future orientation and of self-esteem. Each question has dichotomous answers: 0 no, 1 yes (presence of a characteristic in the area of depression) for a possible range $0-15$. For total scores between 0 and 5 the level of depression is usually considered normal, while total scores higher than 5 express different levels of depression. Among our participants, the Cronbach's alpha was good at both waves (pre-test $=0.70$, post-test $=0.90$ ).

We also used the Italian short version of Index of Basic Activities of Daily Living (BADL; [23,36]). This questionnaire is a well-validated measure of functional outcomes and it includes self-evaluation of independence and/or need of some help in mobility and self-care abilities in 6 areas such as feeding, bathing, dressing, walking, and bowel and bladder control. Each question has dichotomous answers: 0 by oneself, no help, 1 with help for a possible range 0-6. The Cronbach's alpha was very good at both waves (pre-test $=0.80$, post-test $=0.88$ ).

We also administered the Tinetti Assessment Tool [37] for evaluating gait and balance in older people. This test is a task performance exam, which quantifies the motor performance and identifies the subjects at risk of falling by two scales: the Tinetti Balance Scale o BPOMA, which assesses the characteristics of sitting station, postural passages, and erect station, and the Tinetti Gait Scale o GPOMA, which assesses the characteristics of walking.

Finally, all the participants were weighed at pre-test and post-test and we calculated BMI by the way of an electronic balance.

All these measures were collected by specially trained researchers.

\subsection{Strategy of Analysis}

We used Wilcoxon test for dependent samples for ana- lyzing the presence of differences between pre-test and post-test for the whole set of measures and for the whole group of participants (Table 1).

Besides, we used Wilcoxon test for dependent sample for analyzing the presence of differences between pre-test and post-test separately in the sub-groups of men and women (data reported directly in the text). For evaluating the effectiveness of the intervention we calculated the width of a not parametric effect size, which is more appropriate with very little samples than other kinds of measures [38]. We also used Mann-Whitney test for independent samples for analyzing the presence of differences between men and women separately in each time (Table 2)

Finally, in all the cases we describe our data using both median, which may be more adequate than other descriptive measures in very little sample, and mean and standard deviation.

\section{RESULTS}

As we hypothesised we did not find any significant changes between pre-test and post-test with respect to psychological aspects, such as general health perception, depression, and activities of daily living as they were perceived by the older people (Table 1). However, general health perception showed some tendency to increase between pre-test and post-test.

With respect to the physical performance as it is measured by Tinetti test, we found a relevant increase of the balance between pre-test and post-test, while the gait was stable.

In all the above mentioned aspects such as psychological characteristics and physical performance, we did not find any statistical differences between men and women in both waves (these data are available at the first author). However, the effect of the intervention on the balance (measured by the Tinetti Balance Scale) was greater for women than for men. For women: Pre-test: median $=10.0, \mathrm{M}=10.43$, D.S. $=3.10$; Post-test: median $=13.00, \mathrm{M}=13.43$, D.S. $=2.57 ; \mathrm{Z}=-2.375, \mathrm{p}<$ $0.02, \mathrm{ES}=0.63$. For men: Pre-test: median $=10.0, \mathrm{M}=$ 10.40 , D.S. $=1.67$; Post-test: median $=12.00, \mathrm{M}=9.40$, D.S. $=5.18 ; \mathrm{Z}=-0.137, \mathrm{p}=0.89, \mathrm{ES}=0.04$.

In relation to the physical condition we found significant and positive changes between pre-test and post-test for every aspect considered in the study: in general, participants decreased their weight, BMI and also waist circumference (Table 1).

With respect to the physical condition, as it was reasonable to expect, we also found in each wave separately significant gender differences (Table 2): women in general weighted less and they had lower BMI and waist 
Table 1. Wilcoxon test for dependent samples on psychological and physical indicators of adjustment-difference between pre and post-test.

\begin{tabular}{lcccccccc}
\hline Variable & $\mathrm{Z}$ & $\mathrm{N}$ & Sig. ${ }^{1}$ & $\begin{array}{c}\text { Effect size } \\
\text { (ES) }\end{array}$ & \multicolumn{2}{c}{ Median } & \multicolumn{2}{c}{ Means (St. dev.) } \\
\cline { 8 - 9 } & & & & & Pre-test & Post-test & Pre-test & Post-test \\
General Health Perception & -1.134 & 18 & 0.26 & 0.19 & 2 & 2 & $2.10(0.64)$ & $2.35(0.61)$ \\
GDS & -0.114 & 18 & 0.91 & 0.02 & 3 & 4 & $4.65(3.72)$ & $5.12(4.49)$ \\
BADL & -0.287 & 18 & 0.77 & 0.05 & 5 & 6 & $4.47(1.84)$ & $4.59(2.03)$ \\
Tinetti Balance & -1.663 & 12 & 0.09 & 0.34 & 11 & 12.50 & $10.42(2.50)$ & $11.75(4.20)$ \\
Tinetti Gait & -1.000 & 12 & 0.32 & 0.20 & 6.50 & 6.50 & $5.92(3.09)$ & $5.83(3.21)$ \\
Weight & -2.001 & 12 & 0.04 & 0.41 & 66.30 & 61.60 & $65.28(12.61)$ & $63.79(12.83)$ \\
BMI & -2.353 & 12 & 0.02 & 0.50 & 24.21 & 23.40 & $24.50(3.09)$ & $23.93(3.25)$ \\
Waist circumference & -2.689 & 12 & 0.007 & 0.57 & 94.50 & 93.50 & $93.75(14.09)$ & $91.75(14.02)$ \\
\hline
\end{tabular}

${ }^{1}$ We considered till $\mathrm{p}<0.10$ because of the very little sample size.

Table 2. Mann-Whitney test for independent samples on psychological and physical indicators of adjustment-significant gender differences.

\begin{tabular}{lccccccc}
\hline Variable & $\mathrm{U}$ & $\mathrm{N}$ & Sig. $^{2}$ & \multicolumn{3}{c}{ Men } & \multicolumn{2}{c}{ Women } \\
\cline { 6 - 8 } & & & & Median & Means (St. dev.) & Median & Means (St. dev.) \\
\hline Weight pre-test & 3.00 & 12 & 0.02 & 76.30 & $74.96(9.51)$ & 54.60 & $58.37(9.87)$ \\
Weight post-test & 3.00 & 12 & 0.02 & 76.10 & $73.94(9.37)$ & 54.70 & $56.54(9.80)$ \\
BMI pre-test & 6.50 & 12 & 0.07 & 26.87 & $26.55(2.65)$ & 23.32 & $23.04(2.61)$ \\
BMI post-test & 3.00 & 12 & 0.02 & 25.90 & $26.18(2.47)$ & 22.60 & $22.31(2.83)$ \\
Waist circumference pre & -2.353 & 12 & 0.02 & 103.00 & $105.00(7.75)$ & 90.00 & $85.71(11.97)$ \\
Waist circumference post & -2.689 & 12 & 0.007 & 103.00 & $103.4(7.67)$ & 86.00 & $83.43(11.28)$ \\
\hline
\end{tabular}

${ }^{2}$ We considered till $\mathrm{p}<0.10$ because of the very little sample size.

circumference than men. Furthermore, the effect of the intervention on two out of three aspects of the physical condition considered in the present study (weight and BMI) was greater for women than for men. For weight: Women $\mathrm{Z}=-1.690, \mathrm{p}<0.09$, ES $=0.45$; Men $\mathrm{Z}=-1.084$, $\mathrm{p}=0.28, \mathrm{ES}=0.34$. For BMI: Women $\mathrm{Z}=-2.028, \mathrm{p}<$ $0.04, \mathrm{ES}=0.54$; Men $\mathrm{Z}=-1.214, \mathrm{p}=0.283, \mathrm{ES}=0.38$.

However the effect of the intervention was similar in women and men with respect to waist circumference. For Waist circumference: Women $\mathrm{Z}=-2.060, \mathrm{p}<0.04$, $\mathrm{ES}=0.55 ;$ Men $\mathrm{Z}=-1.857, \mathrm{p}<0.06, \mathrm{ES}=0.59$.

Generally speaking the intervention was showed to have medium-large effect size with respect to the physical performance and condition.

\section{DISCUSSION AND CONCLUSIONS}

This study was aimed at investigating the effect of the participation at an aerobic physical training in senior citizens who were slightly cognitively impaired and who lived in a residential care facility. More specifically the study was aimed at investigating the changes between pre-test and post-test with respect to psychological and self-report characteristics, as the perception of health in general, depression and abilities of daily living, physical performance, in terms of balance and gait, and the physical condition, in terms of weight, BMI and waist circumference.

As expected we did not find any change in general health perception and depressive feelings. We also did not find any change in the perception of abilities of daily living in the elderly people. For certain aspects these findings seemed to confirm what we have already underlined in a previous study [29]. In this previous study we found that to change the general health perception and the negative self perception of senior people living in 
residential care facilities is much more difficult than to change other aspects, as the positive self perception and the perception that health may limit physical activity. However, we need also to reflect on the specific characteristics of the participants at the present study. At first, the participants at the present study already suffered for some limitations at their autonomy from the beginning: three of them used some aids. Considering this condition, the fact that they did not get worse along time may be considered a success of the intervention. However, we lack a comparable control group in order to be able to claim this phenomenon as a positive effect of the participation at the training of physical activity. At second, contrarily to what was shown in some previous studies about the positive effect of physical activity on depression in senior citizens [39], we found that depression was stable between pre-test and post-test and it was even slightly higher at the post-test than at the pre-test. We certainly need to further investigate this important point. However, we also have to consider that the age of the participants at the present study is much higher than the ages of the participants at the above mentioned studies.

We found greater evidence of the effectiveness of the intervention on the physical performance and the physical condition than on the psychological and self report aspects. At first we found a relevant improvement of the physical performance in terms of balance. This finding confirmed the study by Harada and collegues [6] on the possibility of improving the physical functioning of institutionalized elderly people by the way of specific training programs. With respect to the fact that the intervention seemed more effective in changing the balance rather than the gait of the senior people, our findings suggested that the balance might be easier to change in short period, while long period may be necessary for changing the gait aspects. At second we found that the intervention was very powerful in ameliorating the physical condition of the senior citizens, contributing at decreasing their weight, BMI, and waist circumference. This finding extended the results of a series of previous studies $[8,29,39,40]$, which underlined different potential benefits of the participation at physical training for the elderly people, in a very old group of participants with slight cognitive impairment. We think that this finding is very comforting, because it showed that a moderate but structured and regular physical training (that lasted for 15 weeks only) may promote a decrease in the body weight, and consequently in the BMI, contributing to a great improvement of the functional condition of senior citizens who are living a condition of general frailty. That is a condition, as it is meant by Fried and Walston [41-43], that may put these senior people at great risk of general disability and co morbidity. At third, we found the participation at the training of physical activity was particularly effective in the case of women. This also is a relevant finding considering that the life expectancy of women is currently increasing much more than that of men [26].

This study has several limitations and among the most important there are the little sample size and the lack of an equivalent control group. These limitations do not allow us to generalize our findings to different situations and populations. Furthermore, although we are aware that the objective clinical parameters as bloody pressure and biochemical texts may be very difficult to change in short periods in senior citizens and also that some previous studies doubted that these clinical parameters may be assumed as efficient predictors of the general health condition of the older people [14], yet we have to admit the lack of these measures in our study.

Despite these and other limitations, our study gives some interesting cues. At first it showed the benefits of the participation at a training of physical activity for institutionalized senior citizens. This represents both a confirmation and an extension of what we already showed in some previous studies that focused only on self-report measures [28,29]. At second it underlined that also in critical condition, as that of the elderly people living in residential care facility and slightly cognitively impaired, the introduction of a relatively simple training may have positive effects on the individual functioning in short time.

\section{ACKNOWLEDGEMENTS}

The third author wants to acknowledge the contribution of Regione Piemonte, Direzione Sanità-Settore Igiene e Sanità Pubblica at this study.

\section{REFERENCES}

[1] Kramer, A.F., Colcombe, S.J., McAuley, E., Eriksen, K.I., Scalf, P., Jerome, G.J., Marquez, D.X., Elavsky, S. and Webb, A.G. (2003) Enhancing brain and cognitive function of older adults through fitness training. Journal of Molecular Neuroscience, 20(3), 213-221.

[2] Spirduso, W.W., Francis, K.L. and MacRae, P.G. (2005) Physical dimensions of aging. Human Kinetics, Champaign.

[3] Stephens, T. (1988) Physical activity and mental health in the United States and Canada: Evidence form four populations surveys. Preventive Medicine, 17(1), 35-47.

[4] Malbut-Shennan, K. and Young, A. (1999) The physiology of physical performance and training in old age. Coronary Artery Diseases, 10(1), 37-42.

[5] Lavile d'Epinay, C. and Spini, D. (2007) Le grand age. Un domaine de recherché récent. Gérontologie et société, 123, 31-54. 
[6] Harada, N., Chiu, V., Fowler, E., Lee, M. and Reuben, D.B. (1995) Physical therapy to improve functioning of older people in residential care facilities. Physical Therapy, 75(9), 830-838.

[7] Folstein, M., Folstein, S. and McHugh, P.R. (1975) Mini-Mental State: A practical method for grading the cognitive state of patients for the clinician. Journal of Psychiatric Research, 12(3), 189-198.

[8] Netz, Y., Wu, M.-J., Becker, B.J. and Tenenbaum, G. (2005) Physical activity and psychological well-being in advanced age: A meta-analysis of intervention studies. Psychology and Aging, 20(2), 272-284.

[9] Wang, L., Larson, E.B., Bowen, J.D. and van Belle, G. (2006) Performance-based physical function and future dementia in older people. Archives of Internal Medicine, 166(10), 1115-1120.

[10] Apiovan, C., Frey, C., Wood, G.C., Rogers, J.Z., Still, C.D. and Lensen, G.L. (2002) Body mass index and physical function in older women. Obesity Research, 10(8), 740-747.

[11] Bohannon, R.W., Brennan, P.J., Pescatello, L.S., Marschke, L., Hasson, S. and Murphy, M. (2005) Adiposity of elderly women and its relationship with self-reported and observed physical performance. Journal of Physical Therapy, 28(1), 10-13.

[12] McAuley, E. and Rudolph, D. (1995) Physical activity, ageing, and psychological well being. Journal of Aging and Physical Activity, 3(1), 67-98.

[13] Lavile d'Epinay, C., Pin, S. and Spini, D. (2001) Présentation de Swilso-o, une étude longitudinale suisse sur la grand age. L'exemple de la dynamique de la santé fonctionnelle. L'Année Gérontologique, 15, 78-96.

[14] van der Bij, A.K., Laurant, M.G.H. and Wensing, M. (2002) Effectiveness of physical activity interventions for older adults. American Journal of Preventive Medicine, 22(2), 120-133.

[15] Segulin, N. and Deponte, A. (2007) The evaluation of depression in the elderly: A modification of the geriatric depression scale (GDS). Archives of Gerontology and Geriatrics, 44(2), 105-112.

[16] Biderman, A., Cwikel, J., Freid, A.V. and Galinsky, D.J. (2002) Depression and falls among community dwelling elder people. A search for common risk factors. Journal of Epidemiological Community Health, 56(8), 631-636.

[17] Ketcham, C.J. and Stelmanch, G.E. (2001) Motor learning in older adults: Foundation and perspective. Meyer \& Meyer, Aachen, Germany.

[18] Scheffer, A.C., Schuurmans, M.J., van Dijk, N., van der Hooft, T. and de Rooj, S.E. (2008) Fear of falling: Measurement strategy, prevalence, risk factors and consequences among older persons. Age and Ageing, 37(1), 19-24.

[19] Costa, G., Migliardi, A. and Gnavi, R. (2006) Verso un profilo di salute (towards a profile of health). Servizio Centrale Comunicazione, Città di Torino, Turin, Italy.

[20] Zhang, J.G., Ishikawa-Takata, K., Yamazaki, H. and Ohta, T. (2004) Is a type A behavior pattern associated with falling among the community-dwelling elderly? Archives of Gerontology and Geriatrics, 38(2), 145-152.

[21] Berg, W.P., Alessio, H.M., Mills, E.M. and Tong, C. (1997) Circumstances and consequences of falls in independent community-dwelling older adults. Age and Age- ing, 26(4), 261-268.

[22] McAuley, E. (1994) Physical activity and psychosocial outcomes. In: Bouchard, C., Shepard, R.J. and Stephens, C. Eds., Physical Activity, Fitness and Health, Human Kinetics, Champaign, 551-568.

[23] Inzitari, M., Di Carlo, A., Baldereschi, M., Pracucci, G., Maggi, S., Gandolfo, C., Bonaiuto, S., Farchi, G., Scafato, E., Carbonin, P. and Inzitari, D. (2006) Risk and predictors of motor-performance decline in a normally functioning population-based sample of elderly subjects: The Italian longitudinal study on aging. Journal of the American Geriatrics Society, 54(2), 318-324.

[24] American College of Sports Medicine (2000) ACSM's guidelines for exercise testing and prescription. 6th Edition, Lippincott, Williams \& Wilking, Baltimore.

[25] Baker, M.K., Atlantis, E. and Fiatarone Singh, M.A. (2007) Multi-modal exercise programs for older adults. Age and Ageing, 36(4), 375-381.

[26] World Health Organisation (2002) Active ageing: A policy framework. Ageing and Life Course Team, Noncommunicable Disease Prevention and Health Promotion Department, World Health Organisation, Geneva.

[27] Ciairano, S., Musella, G., Gemelli, F., Liubicich, M.E., Rabaglietti, E. and Roggero, A. (2006) Un intervento di promozione dell'attività motoria e la salute fisica $\mathrm{e}$ psicologica degli anziani all'interno di una residenza: valutazione di processo e di risultato (An intervention of promotion of the motor activity and the physical and psychological health of the elderly inside a residential care facility: Trial and result assessment). Giornale Italiano di Psicologia dello Sport, 1, 3-11.

[28] Ciairano, S., Musella, G., Gemelli, F., Liubicich, M.E., Rabaglietti, E. and Roggero, A. (2006) Interventi di promozione dell'attività motoria per gli anziani e formazione degli istruttori: Punti di forza e criticità (Interventions of promotion of the motor activity for the elderly ones and training of the instructors: Strength and waik points). Giornale Italiano di Psicologia dello Sport, 1, 13-21.

[29] Ciairano, S., Liubicich, M.E. and Rabaglietti, E. (2010) The effects of a physical activity programme on the psychological wellbeing of older people in a residential care facility: An experimental study. Ageing \& Society, 30(4), 609-626.

[30] Bandura, A. (1997) Self-efficacy: The exercise of control. Freedman and Company, New York.

[31] Associazione Italiana di Psicologia (1997) Codice Etico della ricerca psicologica (Ethical code for psychological research). AIP, Roma, IT.

[32] ISTAT (National Institute of Statistics) (2006) Annuario statistico italiano 2006 (Statistical Italian Yearbook-2006). ISTAT, Roma.

[33] Ware, J.E. and Jr. Sherbourne, C.D. (1992) The MOS 36-item short form health survey (SF-36). Conceptual framework and item selection. Medical Care, 30(6), 473-481.

[34] Apolone, G. and Moscone, P. (1998) The Italian SF-36 health survey translation, validation and norming. Journal of Clinical Epidemiology, 51(11), 1025-1036.

[35] Yesavage, J.A., Rose, T.L., Lum, O., Huang, V., Adey, M. and Leirer, V.O. (1983) Development and validation of geriatric depression screening: A preliminary report. 
Journal of Psychiatric Research, 17(1), 37-49.

[36] Katz, S., Ford, A.B., Moskowitz, R.W., Jackson, B.A. and Jaffe, M.W. (1963) Studies of illness in the aged. The index of ADL: A standardized measure of biological and psychosocial function. Journal of the American Medical Association, 185(12), 914-919.

[37] Tinetti, M.E. (1986) Performance-oriented assessment of mobility problems in elderly patients. Journal of the American Geriatrics Society, 34(2), 119-126.

[38] Valentine, J.C. and Cooper, H. (2003) Effect size substantive interpretation guidelines: Issues in the interpretation of effect sizes. What Works Clearinghouse, Washington, DC.

[39] McMurdo, M.E.T. and Rennie, L. (1993) A controlled trial of exercise by residents of old people's house. Age and Ageing, 22(1), 11-15.
[40] Evans, W.J. (1999) Exercise training guidelines for the elderly. Medicine \& Science in Sports \& Exercise, 31(1), 12-17.

[41] Fried, L.P. and Walston, J. (1998) Frailty and failure to thrive. In: Hazzard, W.R., Blass, J.P., Ettinger, W.H.Jr., Halter, J.B. and Ouslander, J. Eds., Principles of Geriatric Medicine and Gerontology, 4th Edition, McGraw Hill, New York, 1387-1402.

[42] Fried, L.P., Tangen, C.M., Walston, J., Newman, A.B., Hirsch, C., Gottidiener, J., Seeman, T., Tracy, R., Kop, W.J., Burke, G. and McBurnie, M.A. (2001) Frailty in older adults: Evidence for phenotype. Journal of Gerontology A Biological Sciences Medical Sciences, 56(3), 146-156.

[43] Walston, J. and Fried, L.P. (1999) Frailty and the older man. Medical Clinics of North America, 83(5), 1173-1194. 